\title{
TECHNOLOGY TRANSFER - WHEN, WHY, ISSUES AND ADVANTAGES
}

\author{
David F. Sutter, IREAP - University of Maryland, College Park, MD, USA \\ Bruce P. Strauss, OHEP - U.S. DOE, Washington, D.C. USA
}

\begin{abstract}
BACKGROUND
Technology transfer is a big, complex and widely addressed topic, and there exist many studies on "who, what, when, why and how". The proceedings of the 2003 Forum Technology Transfer of Federally Funded R\&D [1] lists 832 references. Technology transfer is invoked any time the results of research and development move to an anticipated user: from an industrial R\&D laboratory to the production line, from a non profit $R \& D$ center to an entrepreneurial new product developer, from university research centers to commercializers and from federally funded research centers to other scientific users or to industry for commercialization and new product development.
\end{abstract}

\section{Federally Funded Research Centers}

In the U.S., almost all accelerator and storage ring advanced technology $R \& D$ is funded through the Department of Energy's Office of Science (DOE/OS) or the National Science Foundation (NSF). The Federal Government is the largest source of $R \& D$ funds in the U.S. - some $\$ 80$ billion in fiscal year 2003 , and more now! The Department of Defense (DOD), Health and Human Services (HHS), NASA, DOE and NSF together provide $95 \%$ of federal $R \& D$ funding [2]. Almost all advanced technology R\&D for accelerators and storage rings is done at the DOE Government Owned Contractor Operated (GOCO) research centers (ANL, BNL, Fermilab, LBNL, TJNAF, etc.) or at Universities funded through DOE/OS or NSF.

The mandate, policy, procedures, and justification for federally sponsored technology transfer are promulgated through an extensive set of legislation, Executive orders (of the President), and Agency Directives (the latter are particularly important for DOE and NSF); the most prominent of which include the legislation generally referred to as the Bayh-Dole Act that includes the Act itself, the University and Small Business Patent Procedures Act, the Trademark Clarification Act and Executive Order 12591. The important issues of intellectual ownership of technology and transferring ownership, (licensing the technology to industry) are a focus of the Stevenson-Wydler Act. Of relevance to the accelerator-physics and technology communities are the Small Business Innovation Research (SBIR) and Small Technology Transfer R\&D (STTR) programs and establishing the Cooperative Research and Development (CRADA) process.

\section{WHAT IS TECHNOLOGY TRANSFER?}

We see that the business of technology transfer is a high profile activity of interest to policy makers, legislators, industrial leaders and much of the R\&D community. But just what is it? It would seem that it means different things to different folks. Three different definitions are presented in the above cited technology transfer forum [2]. While all three give different slants on what technology transfer is, taken together they give some essential general characteristics. The first notes that technology expertise, know-how (the arts) or facilities may be use for "purposes not originally intended". The second points to the utilization of expertise, know-how, or facilities to fulfill public or private needs, i.e. there is more than commercialization involved. The third definition speaks to "formal transfer" to the commercial sector. All three definitions speak to or infer process, formal or informal.

But the common essence of the definitions of technology transfer is that it is a teaching-learning activity, and that it is bilateral. The essence is to show, tell and demonstrate to the student; to repeat the process; and then to ask the student to repeat the above process back to the teacher. This is the basic strategy in what follows. Success in technology transfer means the students "do it" better than the teacher.

\section{TECHNOLOGY TRANSFER \& BIG CONSTRUCTION PROJECTS}

The modern facilities constructed in support of scientific research are generally "big" in the sense of being many hundreds of millions of dollars. Many of the accelerator-storage ring projects most familiar are in fact considered "mega projects."

The above introduction to technology transfer in federally funded science and its supporting technology R\&D has hopefully made it clear that each federally funded laboratory and university of mandated by government to engage in technology transfer in the formal sense described above. This mandate includes the construction projects, the small, medium and mega projects! Mega projects are construction projects that have "from scratch" construction costs greater than $\$ 500$ million. Familiar examples include the LHC, SNS, SLAC, Fermilab, RHIC, ITER, LHC detectors, etc. [4]

But! In the big (and not so big) projects, constructed to support scientific research, the compelling technology transfer need is to get industry to mass produce high technology items not available in the market place.

The technology transfer process used in support of construction of scientific research facilities is a much more limited, focused and specialized process than the general description given above. In particular the technology R\&D and underlying scientific studies have been carried out with a goal or use in mind - even a generic 
one - for possible use in an accelerator or storage ring. Generally, there is a targeted use! Moreover, commercialization is not a goal. No market is expected to develop as a result of the project. If it does, good, but it is fortuitous, not an intended result. The public benefit is indirect; that is, it will derive potentially from the scientific output of the scientific facility and may be a very long time in being realized. This specialized process of technology transfer is the subject of the sections that follow.

\section{THE TECHNOLOGY TRANSFER PROCESS}

The following sections will address what the authors believe, after long experience, are the major steps and issues involved in executing technology transfer in support of large construction projects. While technology transfer is the heart of a successful production of high technology items, the framework in which it is implemented is of equal importance in insuring a successful subsystem acquisition. Consequently, the larger picture is presented. The following major topics will be covered: The Problem; Prerequisites; Alternative Acquisition Strategies; Contributions of the Project and the Vendors; the Process; and Responsibilities. This will be followed by a section on the technology transfer activity itself. There will be some repetition of ideas in the following this is intentional!

\section{The Problem}

Consider project "AFLIC", a large accelerator-storage ring construction that has been approved for funding and has successfully carried out an intensive program of R\&D to develop high technology devices that improve performance and lower cost. One of the devices developed is the "TAMJI". Three thousand of these are needed for the project, plus spares. The number is important. If only 30 TAMJI's were required, a different acquisition path than that needed for 3000 would and should be followed. The following are assumed:

- The R\&D for project AFLIC has successfully built and tested working models and prototypes of a TAMJI,

- There is no known commercial market for TAMJI's and

- There is no known company that has the TAMJI's technology.

The key here is "successfully". The completeness of the R\&D through models, and prototypes is an essential prerequisite to proceeding to the acquisition process, no matter how many are to be procured. The second and third points determine that the specific technology needed to build TAMJI does not exist in industry. This drives the acquisition strategy for procuring TAMJI's.

The problem is how does project AFLIC get 3000 TAMJI's built on performance specification, cost and schedule?

\section{Prerequisites}

The prerequisites to proceeding to acquisition address two issues: determining if project AFLIC is really ready to proceed with the acquisition process for TAMJI's, and laying the foundation for selecting venders, both in quality and number (more than one may be required or desired).

To repeat a point, the R\&D for TAMJI's must be complete - really complete. Project AFLIC should not go to procurement if it doesn't know what it is doing Judging readiness of TAMJI's for production is a serious test of the AFLIC in-house technical review process. The customary collegiality of physicists and engineers working together is here a disadvantage. What is essential for successful in-house review is ruthless objectivity. This is not nearly as unpleasant as a failed acquisition.

Documentation must be complete. Blueprints, working models and prototypes; specifications, tolerances, materials, lists, etc; performance criteria and specialized testing, acceptance criteria and tests must all completely and thoroughly represent the TAMJI that is to be built and installed in the AFLIC project machines. Doing this is common sense. If the staff that developed AFLIC cannot or does not describe what is needed the procurement is at risk and successful technology transfer is unlikely.

Even if project AFLIC were to decide to build in-house, no such decision should be made without knowledge of what industry can do. In the U.S. a procurement of the type we have presumed will require a "make-buy" analysis. This should be done even if not required. The development of a qualified list of venders should be done by the high level technical people responsible for the development of the TAMJI. This activity should not be delegated to the AFLIC procurement office. That said, the procurement office experts should be involved in developing the vendor list. This is the first step where the TAMJI "team" is to be expanded beyond the original development team.

The follow-on, and maybe part of, the process of developing a vendor list, is identifying the key AFLIC project personnel who are going to work with the TAMJI vendor(s) in-house and at the vendor's site. This should be done before going public with any solicitation. The commitment of the same people for the life of the TAMJI acquisition process is a huge advantage and always appreciated. Institutional memory is important! Both technical and procurement specialists must be part of the AFLIC TAMJI procurement team.

Finally, work out the TAMJI procurement schedule. When does project AFLIC really, really need TAMJI's, at what delivery rate and on what completion date. Realism is the core of the scheduling plans; include time contingency.

\section{Alternatives - Hard and Dangerous Choices}

Even though the hypothetical TAMJI procurement taken as our model presumes a particular procurement strategy, there are three major alternatives. Depending on what a TAMJI is in terms of technical complexity and on 
the availability of qualified vendors, the project AFLIC staff may want to consider all the alternatives. This is particularly true, if a smaller number of items are to be built. The three main alternatives are: build TAMJI's inhouse; have industry design and produce TAMJI's; or have industry build TAMJI's to project AFLIC's print and process.

Building TAMJI's in-house has several attractive features. The most obvious, and most commonly cited, reason is that it simplifies the technology transfer process. "We developed it, and we can best use our people to manufacture it." Another advantage is the project does retain intellectual ownership of the design and performance - and the responsibility. It is also true that the complexities of a complex federal procurement appear to be avoided. However, the project generally does have to hire a production staff including experienced production engineers and supervisors and experienced quality assurance specialists. The other issue that comes up at the end of production is what to do with the standing army.

A number of accelerator/storage ring projects have successfully set up and operated in-house production lines. An example where a large quantity was required is fabrication of the superconducting magnets for Fermilab's Tevatron. About 750 dipoles, 300 quadrupoles and a large assortment of correction magnets were successfully produced by Fermilab. The other example is the U.S. production of insertion magnets for LHC straight sections and interactions. Make buy analyses were done for both cases to justify in-house manufacture. The decision to build the LHC insertion region magnets in the labs participating in the U.S. LHC collaboration was essentially unavoidable because of the small number.

In our hypothetical case of acquiring 3000 TAMJI's the in-house option would not be an attractive one.

The second option is to develop a detailed set of performance specifications and ask industry to design, develop and produce the 3000 TAMJI's. This was the strategy followed by the U.S. Superconducting Super Collider (SSC) project, and a number of contracts were in place when the SSC was cancelled. One advantage is that the entire design and production problem is turned over to industrial experts. The second obvious advantage is that there is no standing army of production personnel for project AFLIC to deal with at the end of production. Moreover, specialty fabrication tooling for building or repairing TAMJI's that may be needed by project AFLIC in the future can be made a deliverable. In choosing industry to design and produce TAMJI's project AFLIC would turn ownership of the design to industry. They do it; they have responsibility for it; they own it. Project AFLIC has no control over the technology used except as specified in the original contract and the performance specifications!

At this point, the presumption used in our model, that the specific TAMJI technology does not exist in industry, becomes critical. This was very true in the case of the SSC magnets. As a consequence, the vendors selected to design and produce TAMJI's are going to have to go through a detailed learning process, duplicating what project AFLIC did. This learning process carries risk and costs. If the technology for TAMJI's is difficult and tricky, these costs can be large.

The third choice is to have industry build 3000 TAMJI's to the prints and process developed in the project AFLIC R\&D program. An advantage of this option is that intellectual ownership of the TAMJI design is retained by the project, but so is the responsibility for performance. The standing army of production specialists is not a problem for project AFLIC, and the specialty tooling or some of it, unique to building TAMJI's can be made a deliverable. The "cons" to this approach are that project AFLIC has the responsibility for TAMJI performance; industry's is to build carefully to the agreed upon (they have to agree!) project AFLIC prints and process. Consequently, project AFLIC must pay conscientious attention to accomplishing the prerequisites described above and to the activities, particularly the technology transfer to be discussed in the following.

Large accelerator-storage ring projects that have very successfully used the industrial build to print and to process option successfully, specific examples include the RHIC [3] and LHC main superconducting magnet acquisitions [4] and the original acquisition of main linac high powered klystrons by SLAC. The specific condition that the TAMJI technology does not exist in industry and the history of successful large system procurements done this way makes the build to print and to process compelling. It is the procurement option presumed in the process described in the following:

\section{Who Brings What to the Process}

The successful acquisition of 3000 TAMJI's requires a strong team approach. Each of the partners, Project and industrial vendor, bring assets. These can also be considered expectations, and we give an overview here.

The project brings a highly developed level of science and technology, and this translates into a strong and capable technical support. The AFLIC folks have the most intimate knowledge of TAMJI's. Project AFLIC has the capability of building additional models and prototypes, important for testing changes in the TAMJI design that may reduce cost or improve performance, or both. The AFLIC project has a powerful in-house need for TAMJI's. This is a market pull tied to success of the AFLIC project and is the source (or should be) of a strong motivation to excel.

The industrial vendor brings experience and capability to mass produce high technology products. This includes a high level of industrial engineering expertise that is essential in adapting the TAMJI design to optimize production, ensure expected or better performance, and hold or reduce cost. Industry has specialized knowledge and hardware to efficiently set up mass production. This is not something research labs are expected to have. They have experience in materials more suitable to production in ways of manufacture that lower parts count, and in ways to simplify a design that do not compromise 
performance but do reduce cost. Industry has established quality control organizations, expertise and techniques. This is part of the life blood of folks whose livelihood depends on large scale, cost effective, successful production. The accelerator storage-ring folks do not have this capability, and it is one of the places where most laboratory construction projects get into trouble.

\section{The Process - What the Project Has to Do}

Successful production of TAMJI's is going to be done by one or more industrial vendors. The first key step is project preparation before entering the procurement process. This was discussed above under prerequisites. The prerequisites being done the project must identify, select, and contract with, well-qualified vendors. In reprise, the technical staff must not leave this to the procurement office. In fact, the selection of production vendors is a major milestone for the AFLIC combined technical-procurement team. The AFLIC team has to become expert in the range of options available under applicable procurement laws and regulations and to work the system to the projects advantage, an important point, particularly in the U.S. system. Project AFLIC does not have to accept the lowest bidder if it is not technically qualified, but the technical and procurement folks have to set this up ahead of time as part of the vendor selection process by writing a strong set of technical qualifications that selected vendors must meet.

Getting the technology transferred is a big part of the process. It begins before the procurement process begins, is an essential part of procurement, is critical in getting production started at the selected vendors and continues in some form through the end of the project

A factor that is frequently overlooked by projects is monitoring the vendor's work consistently and constantly throughout the project - to the bitter end. For a large and costly procurement, such as the TAMJI procurement, monitoring means project AFLIC staff in residence at the vendor's plant. A smart vendor will have his staff witnessing acceptance tests at the AFLIC site. No one should ever assume that everything is going smoothly; "smoothly" must be confirmed by inspection, review and communication done by the project-vendor team.

Another step frequently given insufficient attention is setting up to complete production. A Completion Plan should be made part of the production contract with each vendor. The all important close out and the project's final acceptance of deliverables marks the end of technology transfer.

\section{Responsibilities}

This section discusses the responsibilities of the organization originating the TAMJI procurement, project AFLIC, and the production organization, the industrial vendor. There will be a repetition of points made above, some expansion on issues, and some new points. In a sense this is a summary of the general technology transfer process - the framework in which the actual technology transfer activity lives.
The AFLIC project retains intellectual ownership of the TAMJI design and the responsibility for its performance. If industry builds TAMJI to the project's blueprints and agreed upon process, and TAMJ's don't meet performance, the project is stuck with the consequences. Therefore, project AFLIC has the responsibility to most carefully and clearly prepare the prints, to define the process, specify and carry out final acceptance conditions and tests, and to carry out acceptance tests promptly. Acceptance evaluation through the agreed upon (by project and vendor) acceptance testing is the project's special quality assurance protection. Promptness means problems are found early and kept small and manageable. Finally, the project has the responsibility to pay on time. Prompt payment is part of maintaining good team relations, and these prevent lots of problems, and smooth handling of those problems that do arise.

The industrial vendor accepts the responsibility for mass producing TAMJI's. But this means that he has taken on the responsibility of analyzing, understanding and mastering the TAMJI technology and the responsibility for the build to print and build to process mutually agreed to by both parties. This is the vendor's main line of responsibility and protection. The vendor is also responsible for quality control and assurance - developing the plan, getting it approved by the project, implementing it, and providing documentation for each TAMJI. Good quality assurance is how the vendor ensures that each and every item in the contract gets accomplished successfully and therefore, ensures that its responsibilities are met.

Technology transfer is the responsibility of both project and vendor. It begins with the planning by the project to build 3000 TAMJI's and continues until the last TAMJI is delivered and accepted and the contract is closed out.

\section{TECHNOLOGY TRANSFER}

As can be understood from the discussion above in Background, technology transfer can have many definitions; similarly, even in the very specialized procurement model invoked for this paper, the technology transfer process can vary widely. However, if we approach technology transfer from the stand point of effective bilateral communications some very useful general points can be noted. We therefore subtitle this section as "Communications Times Three".

The goal in solving the problem of getting 3000 TAMJI's built on performance specification, cost and schedule is that there be no unpleasant surprises.

First project AFLIC must have its prerequisites done. Then project AFLIC tells industry what is wanted through carefully prepared presentations; first to all prospective vendors and then with even greater clarity, detail and thoroughness to the vendors selected to build the TAMJI's. Then project AFLIC shows what was done to develop TAMJI's - first to potential vendors and then to selected vendors - by tours of the R\&D and preproduction facilities. Once the vendor is selected there is a joint telling and showing to the vendor's and project's tech- 
nical staff - i.e. the partners in the TAMJI production process that must cover in detail the how and why of what was done to produce the TAMJI model and prototypes. Ideally, selected members of the vendor's staff work through construction of a TAMJI with AFLIC project staff in the AFLIC shops.

The next stage is for the vendor to tell project AFLIC what it is going to do by presenting detailed production plans, suggesting design changes for production optimization, and detailing the quality control plans and procedures. Since good teaching requires strong feedback, project AFLIC must review, review, review and communicate times three. Project AFLIC must give serious consideration to suggested changes - to reduce parts count, to simplify parts and assembly, and to use cost saving and/or higher performing materials. At the end of this process there needs to be formal agreement to proceed along the mutually established paths.

There will be changes in the TAMJI design, particularly at this preproduction stage. In order to manage the essential fluidity of the preproduction changes to the TAMJI design - and during full production runs - there needs to be a formal configuration control process. Because project AFLIC retains intellectual ownership of the design and responsibility, configuration control is primarily a project responsibility. Even so, to ensure a rational and quick response to proposed changes, members of the vendor's technical staff should be included in the configuration control process.

The next step is for the vendor to show the project how to build TAMJI's. This is done by a limited production run of say 30 or so TAMJI's. The success of this depends on the acceptance and testing of design changes possibly by building and testing modified TAMJI's inhouse. Both the project and vendor should be receptive to additional limited production runs. The need for these will depend on the preparation to this point, the success of earlier runs and the effectiveness of the technology transfer, most of which should be complete at this stage.

The next stage is full production. This is where the vendor "Tells and shows the project what they's told em and showed em". But production is not one sided. Project AFLIC has a major responsibility to do acceptance tests immediately on delivery of each TAMJI and, as part of the process, to carefully review the quality control documents delivered with each TAMJI. In addition, any glitch in the production line that affects TAMJI performance needs to be communicated to the Project now. The bottom line is "talk to each other". Both vendor and project are responsible for production. Problems detected early are problems kept small.

Finally, at the end, the Project and the Vendor need to execute the agreed upon close-out plan conscientiously and quickly. Since it is likely that in the future project AFLIC may need to repair or even build a few more TAMJI's there should be the needed technology transfer from vendor back to the project.

\section{ACKNOWLEDGEMENTS}

The authors would like to express their gratitude to the late Andy Mravka, one-time Atomic Energy Commission Fermilab site team member and later DOE Fermilab Site Office Manager, for mentoring and early lessons in the federal procurement process, how to successfully work the system, and how to use the build to print and build to process strategy. We would also like to acknowledge Paul Reardon for mentoring, advice and continual encouragement in the things needed to manage projects successfully. Finally, we must acknowledge the review process introduced to DOE by Ed Temple and carried on by Dan Lehman as an indefatigable source of continuing education.

\section{REFERENCES}

[1] M. D. Wang, et al, "Technology Transfer of Federally Funded R\&D, Perspectives from a Forum," The Rand Corporation, Santa Monica, CA, 2003.

[2] Ibid, page 5 .

[3] D. Fisher, M. Anarella, P. Wanderer "Successful Partnership between Brookhaven National Laboratory and Northrup Grumman Corporation for Construction of RHIC Superconducting Magnets;" IEEE Trans. Appl. Supercond., Vol. 10, No 1, March 2000.

[4] P. Fesia, L. Rossi and S. Stine Krog-Pedersen. "Application of Learning Curve Analysis to the LHC Main Dipole Production," IEEE Trans. Appl. Supercond., Vol. 16, No. 2, June 2006. 